\title{
PAHs in Foliage Dust of Typical Tree Species with Urbanization Gradient in Nanjing, China
}

\author{
Yan Zha', Xin Liu ${ }^{2}$, Jie Tang ${ }^{3}$, Yinlong Zhang ${ }^{1 *}$ \\ ${ }^{1}$ Co-Innovation Center for Sustainable Forestry in Southern China, Jiangsu Province Key Laboratory of Ecological \\ Engineering, Nanjing Forestry University, Nanjing, 210037, China \\ ${ }^{2}$ Co-Innovation Center for Sustainable Forestry in Southern China, Jiangsu Province Key Laboratory of Soil \\ and Water Conservation and Ecological Restoration, Nanjing Forestry University, Nanjing, 210037, China \\ ${ }^{3}$ School of Resources and Environment, Hefei Agricultural University, Hefei, 230036, China
}

Received: 30 June 2017

Accepted: 15 August 2017

\begin{abstract}
The foliar surface of plants can capture atmospheric pollutants. Foliage dust is especially useful for passive adsorption of anthropogenic polycyclic aromatic hydrocarbons (PAHs) present in total suspended particles (TSPs). The objective of this study was to compare the dust-retaining capability of typical trees along an urbanization gradient in Nanjing, China. We also studied the concentrations of 16 PAHs in the foliage dust of four typical tree species. We concluded that the dust-retaining capability of the four typical tree species generally decreased in the order: Firmiana simplex $>$ Symplocos sumuntia $>$ Photinia serrylata $>$ Osmanthus fragrans. The highest amounts of dust per unit leaf area were captured by F. simplex, and the mean values were $84.57,63.11$, and $56.29 \mu \mathrm{g} \cdot \mathrm{cm}^{-2}$ in urban, suburban, and rural areas, respectively. PAH concentrations in foliage dust in urban areas were significantly higher than those in suburban and rural areas. Our results suggested that grooves surrounding the stomata and the distribution of tomentum over the leaf surface were the most important factors affecting the accumulation of dust, by facilitating the capture of fine dust particles, which tend to have higher PAH concentrations than larger particles. Scanning electron microscopy (SEM) of the leaf surface of F. simplex revealed that it was covered by tomentum, with grooves surrounding the stomata, and identified this species as a potential biomonitor for atmospheric pollution. From this study, it is evident that PAH concentration of foliage dust can act as indicator of air pollution.
\end{abstract}

Keywords: PAHs, foliage dust retention, tree species, urbanization

\section{Introduction}

Polycyclic aromatic hydrocarbons (PAHs) are of great environmental concern because of their detrimental effects on environmental quality and human health [1-

*e-mail:ecoenvylz@163.com
2], such as carcinogenic potential towards the skin, lungs, and bladder [3], and can be transported over long distances. Incomplete combustion of organic materials are the main sources of PAHs, which are released into the air from the burning of coal, diesel, oil gas, or other organic substances [4-5].

Particulate matter (PM) is a common air contaminant being widespread throughout the atmosphere. Human 
activities such as coal burning, industrial production, transportation, and construction all emit particulate matter containing various poisonous and harmful substances [6-7]. Dust particles can function as carriers of pollutants, depending largely on their chemical composition in terms of mineral and organic contents [8]. Extremely fine PM can contain highly toxic components, such as heavy metals, polychlorinated biphenyls, PAHs, and other potential carcinogens [9]. Transport of particles and their dry and wet deposition from the ambient atmosphere are related to anthropogenic activities, and affect living beings [10]. PAHs have been detected in numerous environmental media, such as the atmosphere, urban street dust, precipitation, soil, and sediment [11]. Air pollution is a serious health problem throughout the world, although most developing countries place an emphasis on different environmental issues [12]. Over the past decades, huge quantities of PAHs have been released into the atmosphere [13] and the mitigation of PAH pollution has emerged as one of the most challenging tasks for environmental management agencies.

Leaves are sensitive and highly exposed to air pollution, can purify air by capturing atmospheric pollutants [1415], and have been used as indicators to assess the quality of air in urban environments [16]. A major proportion of airborne dust is deposited on the canopies of roadside trees as a result of gravity and/or being impacted onto the leaves because of wind current, where the characteristic of the leaf surface determines the amount retained [1718]. Plants remove pollutants from the air by three means: absorption by the leaves, deposition of particulates and aerosols by leaf surfaces, and fallout of particulates on the leeward side of the vegetation [19]. Nisson et al. [17] reported that re-suspension of fine particulates from a leaf surface is less likely as they are more easily embedded within the leaf boundary layer. It has been estimated that plant canopies remove 711,000 metric tons of air pollutants in the United States annually.

Foliar features, including microstructure, play important roles in determining the efficiency by which plants trap dust particulates. Plants differ significantly in their ability to capture dust, depending on features such as characteristics of stomata, trichomes, epicuticular wax, epidermis, and cuticle. Many studies have shown that species with rough leaf surfaces, with features such as grooves or trichomes are considered more effective accumulators of PM [20-21]. Broad-leaved species with rough leaf surfaces accumulate PM more effectively than did those with smooth surfaces [22]. Another study showed that needles of a number of coniferous species, which had a unique microstructure, could capture PM more effectively than broad-leaved species [23]. Leaves exhibiting a high stomata density tend to retain more dust [24] and can therefore affect the ability of leaves of different plant species to capture PAHs from the air [25-26]. Hence, certain plants species can be used as biomonitors and bioindicators of air pollution, in which case dust interception by these plants allows them to become sinks for atmospheric particulate pollutants.
Due to rapid economic development, population growth, and urbanization, the city of Nanjing in southern China is faced with a serious problem of increasing environmental pollution and urban dust pollution, which has become much worse than in suburban areas in recent years [27]. Thus, it is of great significance to select appropriate plants for protecting the environment and the health of human beings. The purpose of this study was to analyze the amount of dust and PAH concentrations in the foliage dust of four tree species along an urbanization gradient. Using scanning electronic microscopy (SEM) analysis, a better understanding can be gained of the role of tree leaves in capturing atmospheric pollutants in a major area of southern China.

\section{Method and Materials}

\section{Study Area}

Nanjing is one of China's largest cities and a major political, economic, and industrial center in southern China with an area of $6,587 \mathrm{~km}^{2}$ and a population of over 8.27 million. It belongs to a subtropical monsoon climate, with annual rainfall of $1,200 \mathrm{~mm}$ and an average temperature of $15.4^{\circ} \mathrm{C}$. The current study was carried out in the city of Nanjing, which is characterized by high levels of human activity. The study site was an area of afforestation in the city center. The city was divided according to landuse type and distance from the city center, as well as into urban, suburban, and rural areas. The sampling sites were specifically classified into the following: urban areas (31 ${ }^{\circ} 52^{\prime \prime} \sim 32^{\circ} 14^{\prime \prime} \mathrm{N} 118^{\circ} 34^{\prime \prime} \sim 119^{\circ} 14^{\prime \prime} \mathrm{E}$ ), which included eight districts (Xuanwu, Baixia, Gulou, Qinhuai, Jianye, Xiaguan, Yuhuatai, Qixia), with high-density populations and heavy traffic. The suburban areas $\left(31^{\circ} 37^{\prime \prime} \sim 32^{\circ} 36^{\prime \prime} \mathrm{N}\right.$ $118^{\circ} 21^{\prime \prime} \sim 119^{\circ} 06^{\prime \prime} \mathrm{E}$ ), which included three districts (Pukou, Liuhe and Jiangning) with lower traffic and other anthropogenic activities, and rural areas $\left(31^{\circ} 13^{\prime \prime} \sim 31^{\circ} 47^{\prime \prime} \mathrm{N}\right.$ $118^{\circ} 41^{\prime \prime} \sim 119^{\circ} 13^{\prime \prime} \mathrm{E}$ ), which were far from the city center, where the low density of residents and traffic led to low pressure in this area (Lishui and Gaochun; Fig. 1).

\section{Species Sampled}

The sampling of foliage dust was done during summer months (August-September 2016). Four species of tree, namely, Firmiana simplex, Symplocos sumuntia, Photinia serrylata, and Osmanthus fragrans are widely distributed in urban, suburban, and rural areas in Nanjing. Samples were collected in August 2016 after a period of heavy rain and strong wind. For each tree species in each area five trees were selected for sampling. None of the tree leaf samples (100 pieces) were suffering from obvious pests or disease. They were collected from the inner and outer canopies of east-, south-, west-, and north-facing directions at a height of approximately $1.5-3 \mathrm{~m}$ above ground level with a pruner. All sample leaves were carefully collected to minimize the touching 

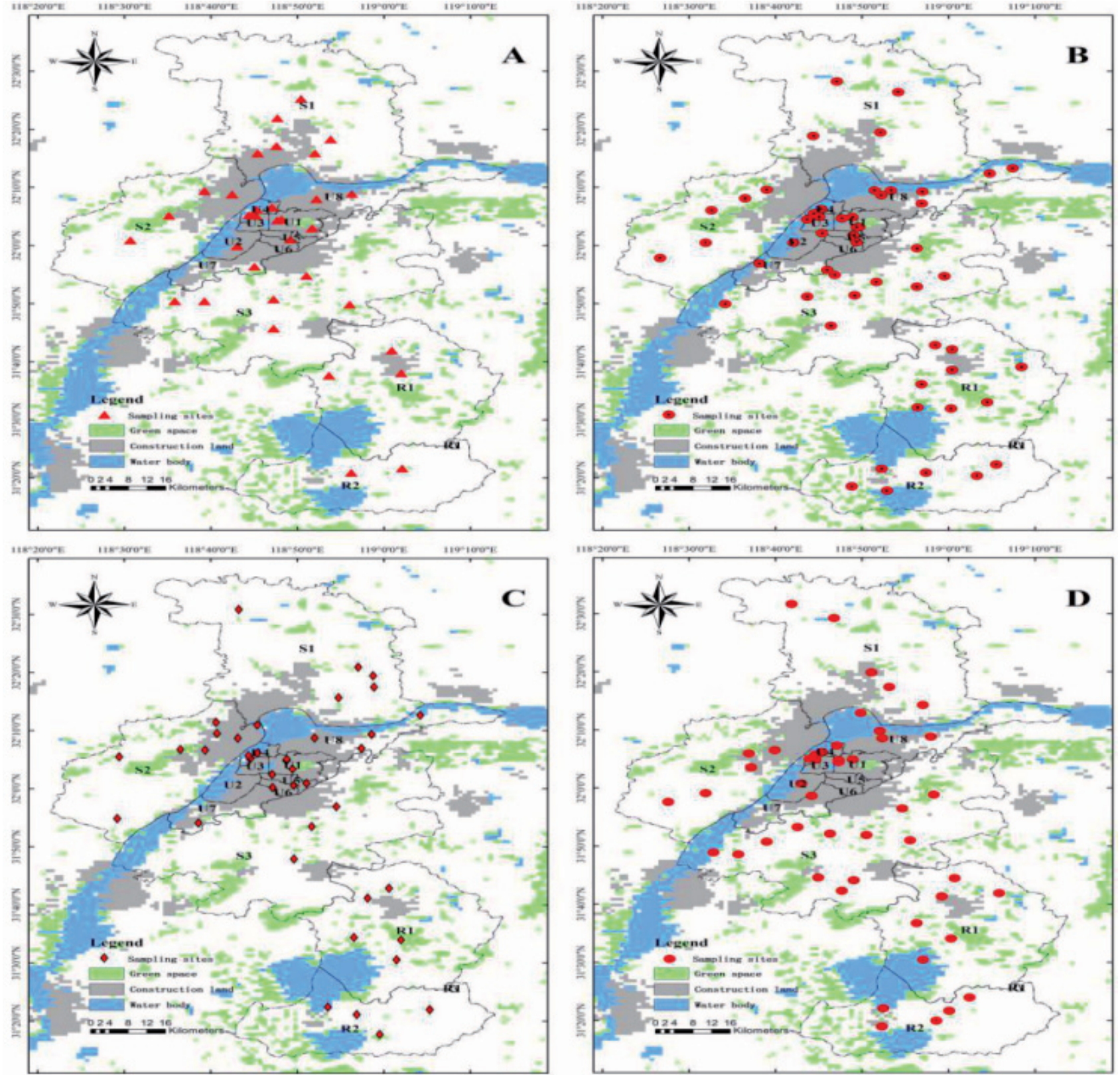

Fig. 1. A: Study area and sampling sites of F. simplex leaves. B: Study ares and sampling sites of O.fragrans leaves. C: Study ares and sampling sites of P. serrulata leaves. D: Study ares and sampling sites of S. sumuntia leaves.

of the leaf surface and were kept in a cool box $\left(-20^{\circ} \mathrm{C}\right)$ during transport and in the laboratory prior to analysis.

\section{Sample Pre-Treatment}

The foliar dust particles were washed down from leaves using deionized water obtained from an ultrasonic cleaner (HS-1010A, Shenzhen, China) [28]. Leaves were placed into a $500-\mathrm{ml}$ plastic container and $250 \mathrm{ml}$ of Milli-Q water was added (Milliporem Bedford, MA, USA). The dust containing the suspension was filtered through a $150 \mu \mathrm{m}$ sieve. The procedure was repeated with $50 \mathrm{~mL}$ Milli-Q water, which was filtered and added to the samples. This $300 \mathrm{~mL}$ of dust-containing suspension was dried with a vacuum freeze-drier (Labconco,
Kansas City, MO, USA) for five days at $-83^{\circ} \mathrm{C}$ to a constant weight and then stored at $-20^{\circ} \mathrm{C}$ until further extraction.

The 20 pieces of sampled leaves were immersed in distilled water for $30 \mathrm{~min}$ and an ultrasonic cleaning instrument (HS-1010A, Shenzhen, China) was applied to separate the attached dust from the leaves. Then the leaves were carefully taken out of the distilled water, which was filtered through a dried, pre-weighed filterpaper whose weight was recorded as $\mathrm{W}_{1}$. The filter paper was subsequently dried for $12 \mathrm{~h}$ at $60^{\circ} \mathrm{C}$, and then weighed and recorded as $\mathrm{W}_{2}$. The difference between $\mathrm{W}_{1}$ and $\mathrm{W}_{2}$ was the weight of the dust on the sampled leaves. The area of each leaf was determined using a leaf area meter and recorded as $\mathrm{S} . \mathrm{M}=\left(\mathrm{W}_{1}-\mathrm{W}_{2}\right) / \mathrm{S}$. 


\section{Scanning Electron Microscopy}

Scanning electron microscopy (SEM) was used to investigate the surface characteristics of leaves and the locations of dust particles. Sections $\left(5 \times 5 \mathrm{~mm}^{2}\right)$ were trimmed from areas between the margin and midrib of leaves. The specimens were coated with a thin conductive film of gold in an ion sputter coater (PELCO-SC-7). Coated specimens were examined and photographed under a field emission scanning electron microscope (JSM-6330F, JAPAN).

\section{Chemicals and Materials}

A composite standard solution of 16 PAHs was purchased from Sigma-Aldrich (Dr, Germany), including Naphthalene (Nap), aceNaphthylene (Acy), aceNaphthene (Acp), fluorene ( $\mathrm{Fl}$ ), phenanthrene (Phe), anthracene (Ant), fluoranthene (Flu), pyrene (Pyr), benzo(a) anthracene $(\mathrm{BaA})$, chrysene (Chr), benzo(b)fluoranthene $(\mathrm{BbF})$, enzo(k)fluoranthene (BkF), benzo(a)pyrene (BaP), dibenzo(a,h)anthracene (DBA), benzo(g,h,i) perylene (BghiP), and indeno (1,2,3-cd)-pyrene (IcdP). In this study, the concentration extracts were analyzed for PAHs using a high-performance liquid chromatograph (HPLC, Shimadzu, LC-20A) with the $4.6 \mathrm{~mm}$ (ID) $\times 250 \mathrm{~mm}$ (L) column and a $310 \mathrm{UV}$ detector at $260 \mathrm{~nm}$. A mixture of acetonitrile (ACN) and water was used as the mobile phase with solvent-gradient method and a flow rate of $1.0 \mathrm{~mL} \cdot \mathrm{min}^{-1}$ at $35^{\circ} \mathrm{C}$.

\section{PAH Extraction}

All PAHs were extracted from dust $(0.5 \mathrm{~g})$ with a $30 \mathrm{~mL}$ mixture of hexane and dichloromethane $(\mathrm{v} / \mathrm{v}=1: 1)$ using an ultrasonic bath for $1.5 \mathrm{~h}$. This step was repeated three times. The solvent fractions were concentrated by a vacuum rotary evaporator and solvent exchanged to hexane. The concentrated extract was cleaned with silica column chromatography $(10 \mathrm{~mm}$ (ID) $\times 350 \mathrm{~mm}(\mathrm{~L}), 10 \mathrm{~g}$ of silica gel, and $20 \mathrm{~mm}$ length of anhydrous sodium sulphate). Then the aliphatic fraction was abandoned by washing it with hexane $(25 \mathrm{~mL})$, while the PAH fraction was washed by dichlomethane (40 mL), followed by filtration through a $0.22 \mu \mathrm{m}$ fiberglass membrane and re-concentration with a gentle stream of nitrogen to exactly $1 \mathrm{~mL}$ though a blowing process at $25^{\circ} \mathrm{C}$. The concentrated extracts were then analyzed for PAHs with a high-performance liquid chromatograph (LC-20AT; Shimadzu, Kyoto, Japan).

\section{Quality Assurance and Quality Control}

All analytical procedures were monitored using strict quality assurance and control measures. During sample analysis, blanks and matrix blanks (PAHs-free) were analyzed. The 16 PAHs were quantified using the reference methods. Experiments to assess foliage dust recovery were conducted by spiking known concentration standards $\left(200 \mathrm{ng} \cdot \mathrm{g}^{-1}\right)$. The foliage dust average recovery ranged from $78.31 \%$ for Nap and $78.32 \sim 102.45 \%$ for the remaining 15 PAHs.

\section{Statistical Analysis}

Two-way ANOVA was used to test for the amount of dust on the surface of leaves and the PAH concentration of foliage dust of the studied areas. As posts, the hot test LSD multiple comparison test was used to explore the significant differences. PCA was used to display the effect of tree species and urbanization on PAH concentrations of foliage dust. Calculations were performed using the SPSS17.0 (SPSS Inc., USA) and Canoco 5.0. Most graphs were constructed using Excel 2012 and origin 9.0.

\section{Results and Discussion}

Effect of Rree Species and Location on the Distribution of PAHs in Foliage Dust

The concentrations of total and individual PAHs in foliage dust of four tree species were determined in urban, suburban, and rural areas of Nanjing (Table 1). In the case of F. simplex, the highest Flu and BghiP concentrations were found in dust collected from urban areas. The concentrations of Nap and Ace from rural areas were significantly higher than those from both urban and suburban areas. This may be because burnt biomass and creosote were the main sources of Nap and Ace in rural areas of Nanjing [29-30]. Concentrations of $\mathrm{Phe}, \mathrm{BkF}$, and $\mathrm{BaP}$ were significantly higher in urban than in rural areas, but no significant difference was obtained between urban and suburban areas. In the case of dust on S. sumuntia, the Acy concentration was significantly higher in urban areas than in suburban and rural areas (Table 1). There were no significant differences in Acy, Phe, and BghiP concentrations between suburban and rural areas $(p>0.05)$. There were significant differences in Ant, Pyr, and $\mathrm{BaP}$ concentrations between urban and rural areas. In the deposited dust on P. serrylata, Nap and Ace concentrations were highest in urban areas. The concentrations of Acy, Phe, and BghiP were significantly different between urban and rural areas, with the Nap concentration in the deposited dust on $O$. fragrans being significantly higher in urban than in rural areas.

Principal component analysis (PCA) showed a complete separation of the tree species based on the concentrations of PAHs in the foliage dust (Fig. 2). The first component (PC1) contributed $55.17 \%$ of the total variance, while the second one (PC2) contributed 14.93\% of the total variance. There are two groups of PAHs separated along the first axis (PC1). The first group of PAHs included BaA, Ace, and Nap. Nap and Ace have been identified as markers of traffic tunnels [31], whereas BaA has been used as a marker for diesel engines [32]. Hence, the results from $\mathrm{PC} 1$ revealed that vehicle emissions were probably a major source of PAHs in foliar dust around 


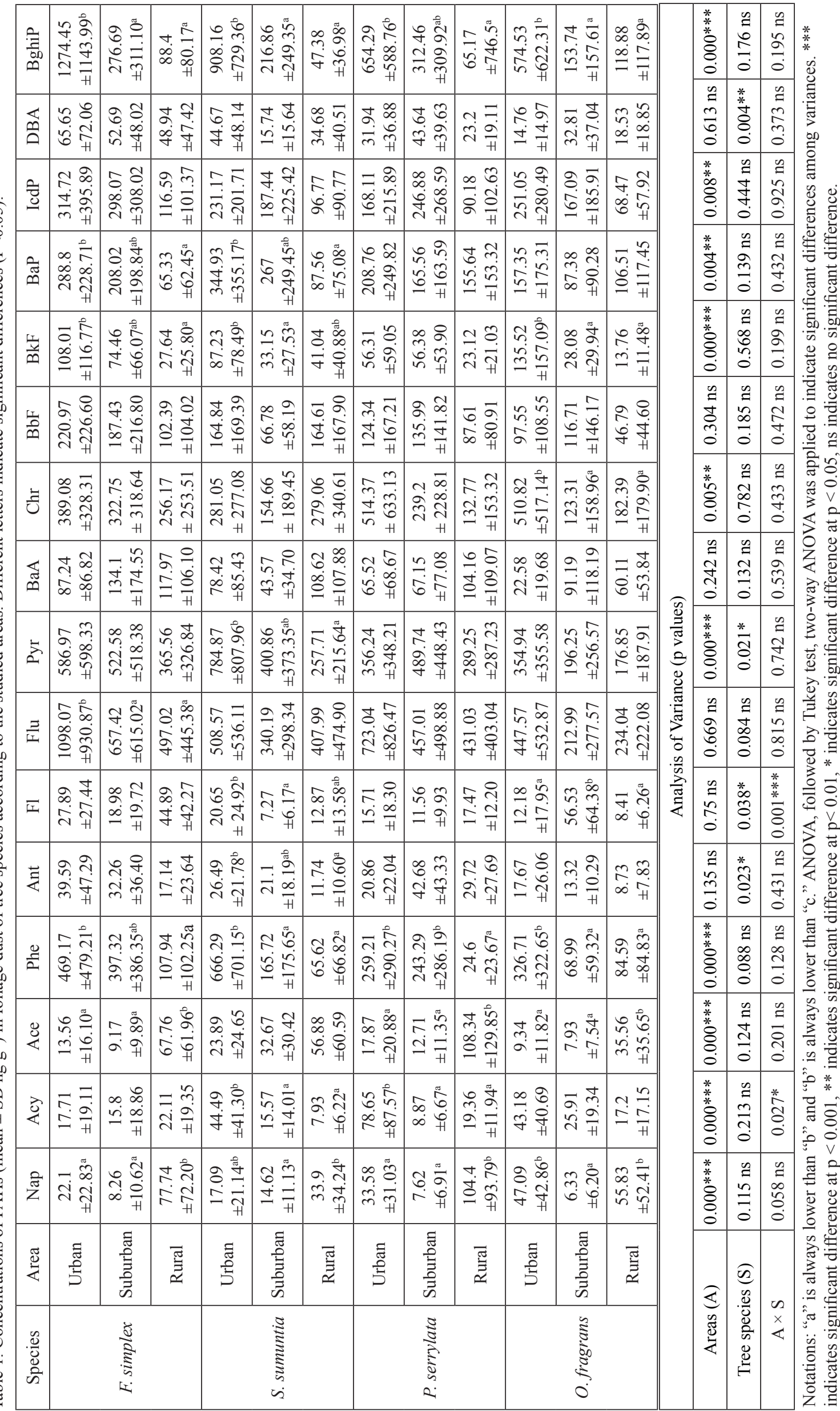


Nanjing. The second group consisted of Fl, DBA, BbF, IcdP, Ant, Phe, BkF, BaP, Flu, Pyr, Chr, BghiP, and Acy. Among these, PAHs, BbF, IcdP, BghiP, and DBA; and $\mathrm{BaP}, \mathrm{Chr}$, Flu, and Pyr also accounted for some loading in this factor. A similar pattern of PAHs found in PC2 was identified from a gasoline engine emission source in a previous study [33]. Fl and Phe were sourced from coke ovens [34]. Therefore, the results from PC2 revealed that gasoline engine emissions and coke ovens were probably major sources of PAHs in foliar dust in Nanjing. There were significant differences in the concentrations of Chr, BaP, IcdP, and DBA $(\mathrm{p}<0.01)$ and Ant, Fl, and Pyr $(p<0.05)$ in the dust from different tree species (Fig. 2). Urbanization significantly increased the concentrations of Nap, Acy, Ace, Phe, Pyr, BkF, and BghiP in the dust $(p<0.001)$, while there was a significant [urbanization $\times$ species] interaction in terms of the concentrations of $\mathrm{Fl}$ $(\mathrm{P}<0.001)$ and Acy $(\mathrm{p}<0.05)$.

PAH concentrations varied substantially along the urban-rural gradient in Nanjing (Fig. 3). The highest PAH level in foliage dust was detected in urban areas, which is likely to be explained by the higher population density and heavy traffic associated with the financial, political, and trade center of the commercial-residential mixed urban zones in Nanjing. The suburban areas were located away from the city center and have relatively small population densities with fewer vehicles than in the urban zones. However, the main petrochemical plants and several chemical companies are located in the Changlu Zone [27], and they are collectively a primary source of PAH pollution in Nanjing. The lowest levels of PAH were found in rural areas, which are sparsely populated with little vehicle traffic, thus the fewest sources of PAH pollution exist in such areas. In agreement with our results, Li et al. [35] reported that adjacent anthropogenic activities had a greater effect on the pollution characteristics of street dust than did land-use types. Therefore, anthropogenic activities were the main source of PAHs in Nanjing.

\section{The Profile Characteristic of PAHs in Foliage Dust}

The 16 PAH compounds were divided into five groups: 2-ring, 3-ring (low molecular weight, LMW), 4-ring (moderate molecular weight, MMW), 5-ring, and 6-ring PAHs (high molecular weight, HMW). In terms of compositional pattern, HMW PAHs (4 to 6 rings), with a mean of $84.28 \%, 82.68 \%$, and $79.32 \%$ of the total $\mathrm{PAH}$ in foliage dust in urban, suburban, and rural areas, respectively, were the predominant PAHs (Fig. 4).

Various investigators have found that foliage dust and street/road dust display differences in terms of physical structure and particle size composition, as well as the environmental behavior of the pollutants contained within the particulate [36-37]. When the two types of dust are present in the same area, the environment becomes an influencing factor, and pollutants can be released over a period of time and area. This was similar to previously reported findings, such as where HMW PAHs contributed

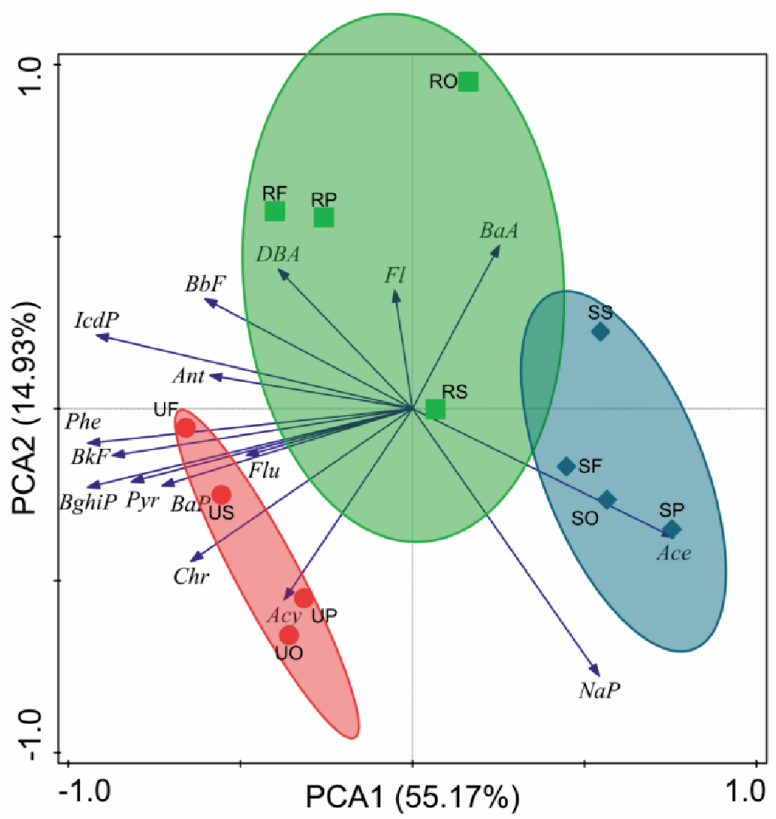

Fig. 2. Principal component biplot of PAHs concentrations of foliage dust of species and study areas. Notations : The initial U: Urban areas, The initial S: Suburban areas, The initial R:Rural aras. S: S. sumuntia, O: O.fragrans, F: F. simplex, P: P. serrylata .

$62 \%$ to $94 \%$ of the total mass of $\sum$ PAHs in the surface dust samples in Guangzhou [38], within which 4- and 5-, and 6-ring PAHs represented $41.6 \%$ and $31.6 \%$, respectively, of the street dust of Beijing [35]. Petrogenic sources are incompletely combusted petroleum products and are primarily composed of LMW PAHs, while HMW PAHs are the pyrogenic products from the combustion of coal, fossil fuel, natural gas, diesel, and gasoline [39]. Wang et al. [38] found that HMW PAHs posed an ecological risk to aquatic environments due to the high concentrations present in road dust. Our results showed that HMW PAHs are important pollution sources that are more toxic and persistent in the environment. In addition, foliage dust reduces the risks of human exposure to toxic PAHs by ingestion or dermal contact.

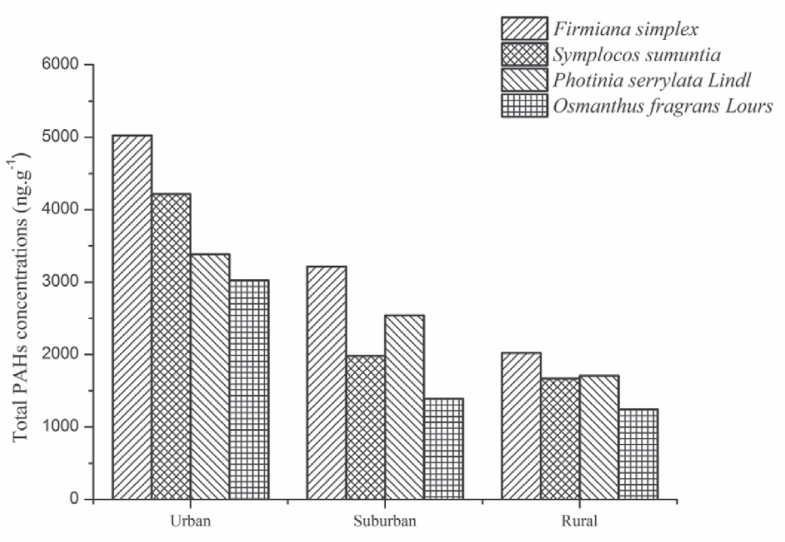

Fig. 3. Total PAHs concentration among tree species. 
Effect of Tree Species and Location on the Amount of Deposited Dust on Leaves

The amount of dust deposited on the leaves of the four tree species studied in urban, suburban, and rural areas of Nanjing are shown in Fig. 5. The two-way ANOVA was used to analyze the effect of tree species and urbanization on the amount of dust on the leaves.

It can be seen that the dust retention of the studied tree species in the same area differed significantly (Fig. 5). Tree species $\left(\mathrm{F}_{\mathrm{A}, \mathrm{S}}=25.406, \mathrm{p}<0.001\right)$ and the degree of urbanization $\left(\mathrm{F}_{\mathrm{A}, \mathrm{S}}=5.812, \mathrm{p}<0.05\right)$ had significant impacts on the amount of dust, while the [interaction species $\mathrm{x}$ urbanization] was significant $\left(\mathrm{F}_{\mathrm{A}, \mathrm{S}}=\right.$ $2.893, \mathrm{p}<0.05)$, suggesting that the species differed in their ability to capture dust from different zones within Nanjing.

The maximum amount of dust was found in urban areas due to increasing pollution, whereas in lowpollution rural areas presented the lowest amounts of dust. The amounts of dust removed by F. simplex leaves were $84.57,63.11$, and $56.29 \mu \mathrm{g} \cdot \mathrm{cm}^{-2}$ in urban, suburban, and rural areas, respectively. The species capturing the least amount of dust in all areas was $O$. fragrans, the values being 22.7, 17.9 , and $9.34 \mu \mathrm{g} \cdot \mathrm{cm}^{-2}$, respectively. Other studies had also shown that the dust amounts on the same urban tree species differed greatly under different pollution intensities [24]. Freer-Smith et al. [40] reported significant effects of both sites and species on the amount of deposited dust. The same conclusion was reached regarding urban dust pollution being much higher than in the suburban areas during the years of the study in Nanjing [27]. Therefore, trees in urban areas performed greater atmospheric pollution elimination from the environment than in rural and suburban areas.

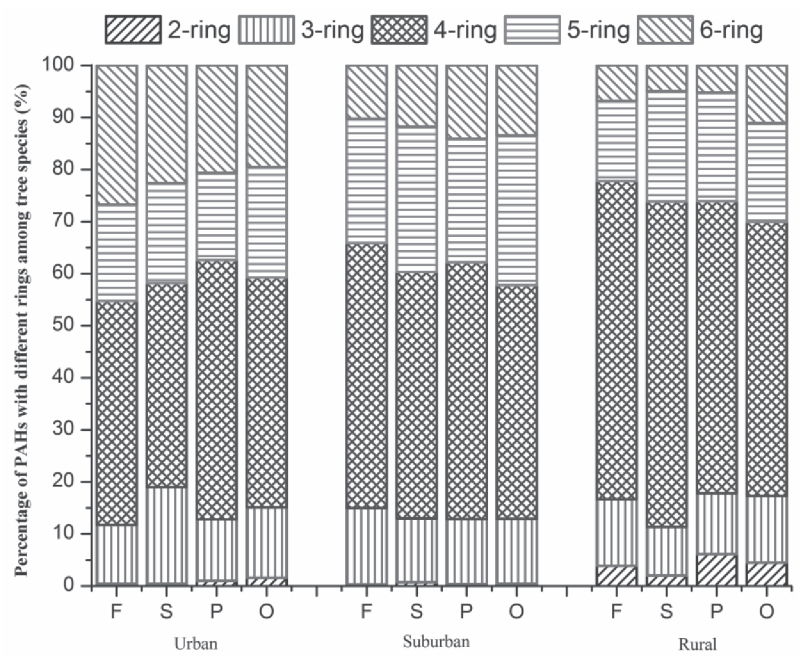

Fig. 4. Composition of PAH homologues in foliage dust with four tree species. F: F. simplex, S: S. sumuntia, P: P. serrylata, $\mathrm{O}:$ O. fragrans.

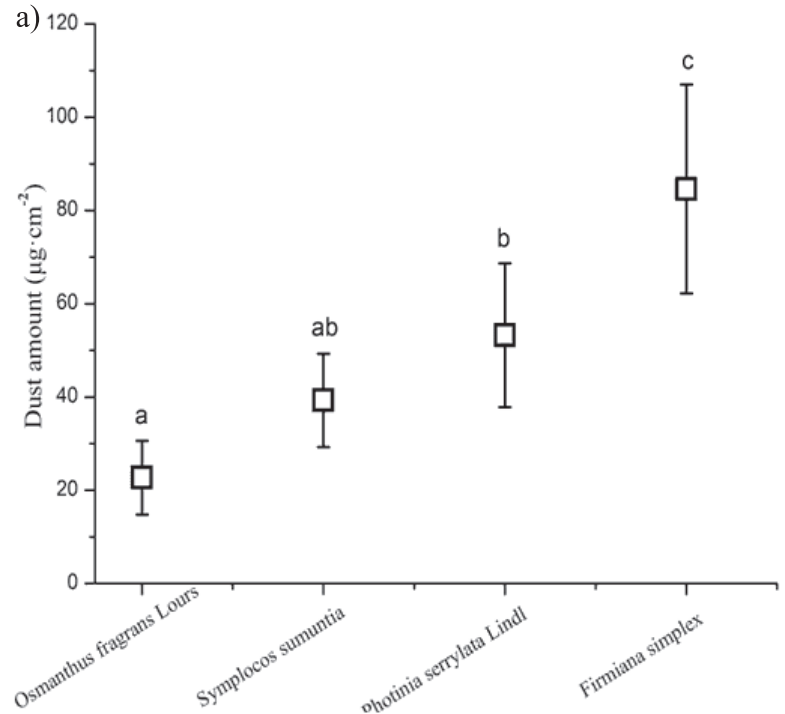

b)

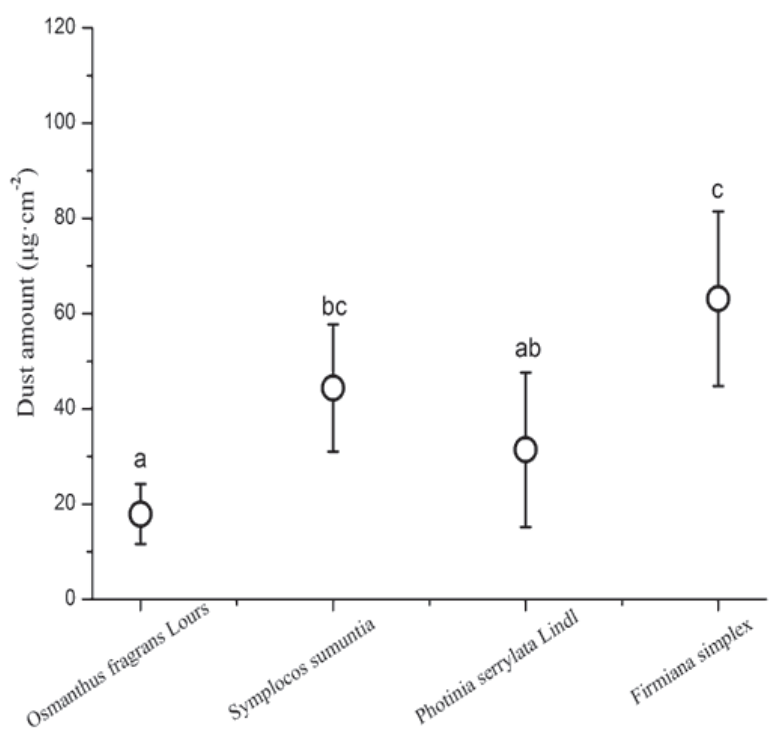

c)

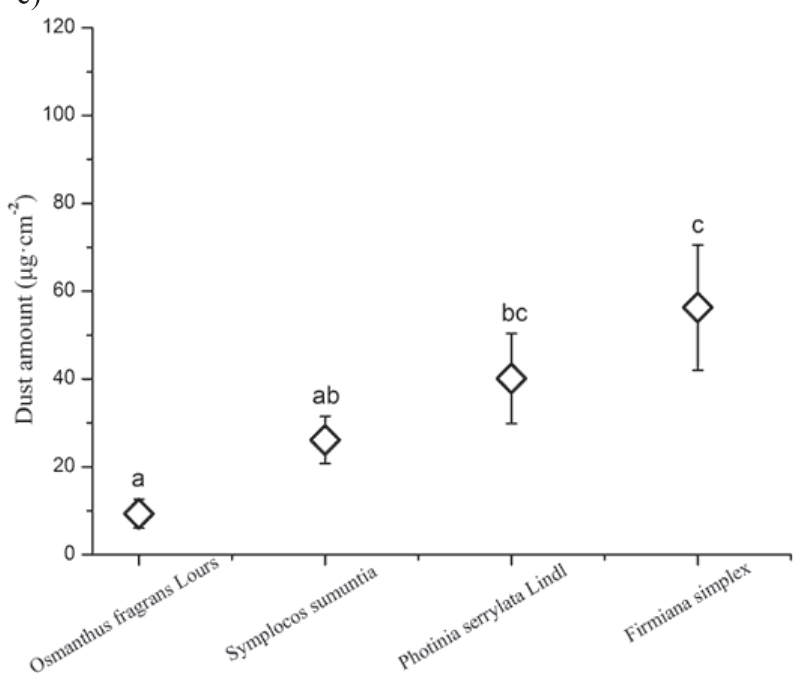

Fig. 5. Amount of deposited dust (mean $\pm \mathrm{SD}$ ) on leaves' surface of the studied species along the urbanization gradient. Notations: a) urban areas, b) suburban areas, c) rural areas. Different letters indicate significant differences $(\mathrm{p}<0.05)$. 


\section{Effects of Morphological Structure Characteristics on the Removal of Dust}

Table 2 presents the surface structural properties of the four tree species used in this study. In terms of leaf shape, $F$. simplex leaves are quite different from those of the other species, being large and palmate, with an undulate margin. O. fragrans leaves have long elliptical leaf forms, while $S$. sumuntia have narrowly elliptic-obovate, with a slightly involute margin. $P$. serrylata leaves are long with an obovate and shape oval. Scanning electron microscopy (SEM) images of the leaf surface structures of the four tree species are presented in Fig. 6.

The stomatal density of $O$. fragrans is $56 \mathrm{~mm}^{-2}$ under 500x magnification (Fig. 6b). Although the stomata density was significantly higher than for the other three tree species, the dust retention capacity of $O$. fragrans was relatively weak. The reason is related to the coverage of leaf surface by hairline and shallow ditch-shaped tissues, and thus leads to the reduction of the contact area for dust and leaf surface (Figs 6a-b). The stomata density of $S$. sumuntia is $19 \mathrm{~mm}^{-2}$ under $500 \mathrm{x}$ magnification (Fig. 6d). The dust retention amount by S. sumuntia was influenced by irregularly corrugated shapes on the periphery of the stomata (Figs 6c-d). The stomata density of $P$. serrylata is $37 \mathrm{~mm}^{-2}$ under 500x magnification (Fig. 6f). The morphological characteristics of $P$. serrylata leaf shows visible epicuticular waxes. The important function of the epicuticular waxes is to reduce leaf water loss. The stomatal density of $F$. simplex is $32 \mathrm{~mm}^{-2}$ under 500x magnification (Fig. 6g). Only in F. simplex is the leaf surface covered with wave-like flexuous rachis and does the lower limit of the cell wall on the leaf surface constitute a dense irregular meshwork (Fig. 6h).

The data from this study in the Nanjing area indicated that the leaves of different tree species had varying abilities to capture dust, a finding that was consistent with the results reported by Mo et al. [41]. Various literature provided evidence of variations between species for dust capture by leaves. The various protrusions, ditch-shaped, stomata, and other features of the leaf surface increase its roughness, thus improving its dust-capturing ability
[42]. However, not all leaf surfaces are ditch-shaped with strong dust-catching abilities. For instance, research has shown that those leaves with relatively large stomatal apertures are preferable for trapping PM than are leaves with regular stomatal arrangements [24]. A finding that is in agreement with our data showed the lower ability of $O$. fragrans to trap PM [43]. Tree species with a large leaf area of tree species allows them to accumulate large amount of PM over trees with smaller leaf area [44]. As a broadleaf species, the dust retention capacity of $F$. simplex is the strongest. The morphological characteristic of F. simplex shows a visible gap-like shape that can capture more PM and prevent it from being resuspended in the atmosphere [45]. Murakami et al. [46] found that greater accumulation by widely the planted ginkgo street tree may be attributed to its wavy walled surface structure. We found that $F$. simplex had surface structural characteristics similar to those of ginkgo. There is also a positive correlation between the amount of tomentum on the leaf surface and the amount of dust removed by a plant [42]. This feature may also contribute to the ability of leaves of $F$. simplex to capture and retain large quantities of dust and hence air pollutants, making it an attractive option for its use in landscaping urban green areas.

\section{The Relationship between Plant Morphologic Characteristics and PAH Concentrations}

Fig. 5 showed that foliage dust on different tree species differed with respect to size and PAH accumulation. Ram et al. [36] found that foliage dust from tree leaves consist of fine particles smaller than $30 \mu \mathrm{m}$. Other researchers have shown that grain size was another factor influencing the accumulation of PAHs. Total PAH concentrations increased as particle size decreased [37]. White PMs comprise dust particles. No secretions were found on the leaf surfaces of the four species studied, so it appears that the leaves trap dust via leaf hair or depressions such as grooves or sunken stomata on their surface (Fig. 7). It can be clearly observed from SEM images that particles on the leaf are spherical in shape and combine to from aggregates with most of the PMs at $<10 \mu \mathrm{m}$. The ability

Table 2. Surface structural properties of the four tree species.

\begin{tabular}{|c|c|c|c|c|c|c|c|}
\hline No. & Tree species & Shape of leaf & $\begin{array}{c}\text { Average of } \\
\text { leaf area }\left(\mathrm{cm}^{2}\right)\end{array}$ & Epicuticular wax & Cuticle & Stomata & Trichomes \\
\hline 1 & F. simplex & $\begin{array}{c}\text { Broadly ovate or } \\
\text { oval elliptical }\end{array}$ & 208.84 & $\begin{array}{c}\text { Elongated } \\
\text { epidermic like } \\
\text { waves }\end{array}$ & $\begin{array}{c}\text { Disorganized grid } \\
\text { and curved deep } \\
\text { ridge }\end{array}$ & $\begin{array}{c}\text { Density and } \\
\text { ellipse }\end{array}$ & $\begin{array}{c}\text { Thinly } \\
\text { Pubescent }\end{array}$ \\
\hline 2 & S. sumuntia & $\begin{array}{c}\text { Narrowly } \\
\text { elliptic-obovate }\end{array}$ & 15.23 & Inconspicuous & Smooth & $\begin{array}{c}\text { Size almost } \\
\text { half }\end{array}$ & NR \\
\hline 3 & P. serrylata & Long ellipse & 12.69 & Inconspicuous & Smooth & $\begin{array}{c}\text { Organized and } \\
\text { ellipse }\end{array}$ & NR \\
\hline 4 & O. fragrans & $\begin{array}{c}\text { Long ellipse or } \\
\text { lanceolate }\end{array}$ & 23.24 & Wrinkled less & Slight papillose & $\begin{array}{c}\text { Organized and } \\
\text { globose }\end{array}$ & NR \\
\hline
\end{tabular}

Notations: NR not recorded 

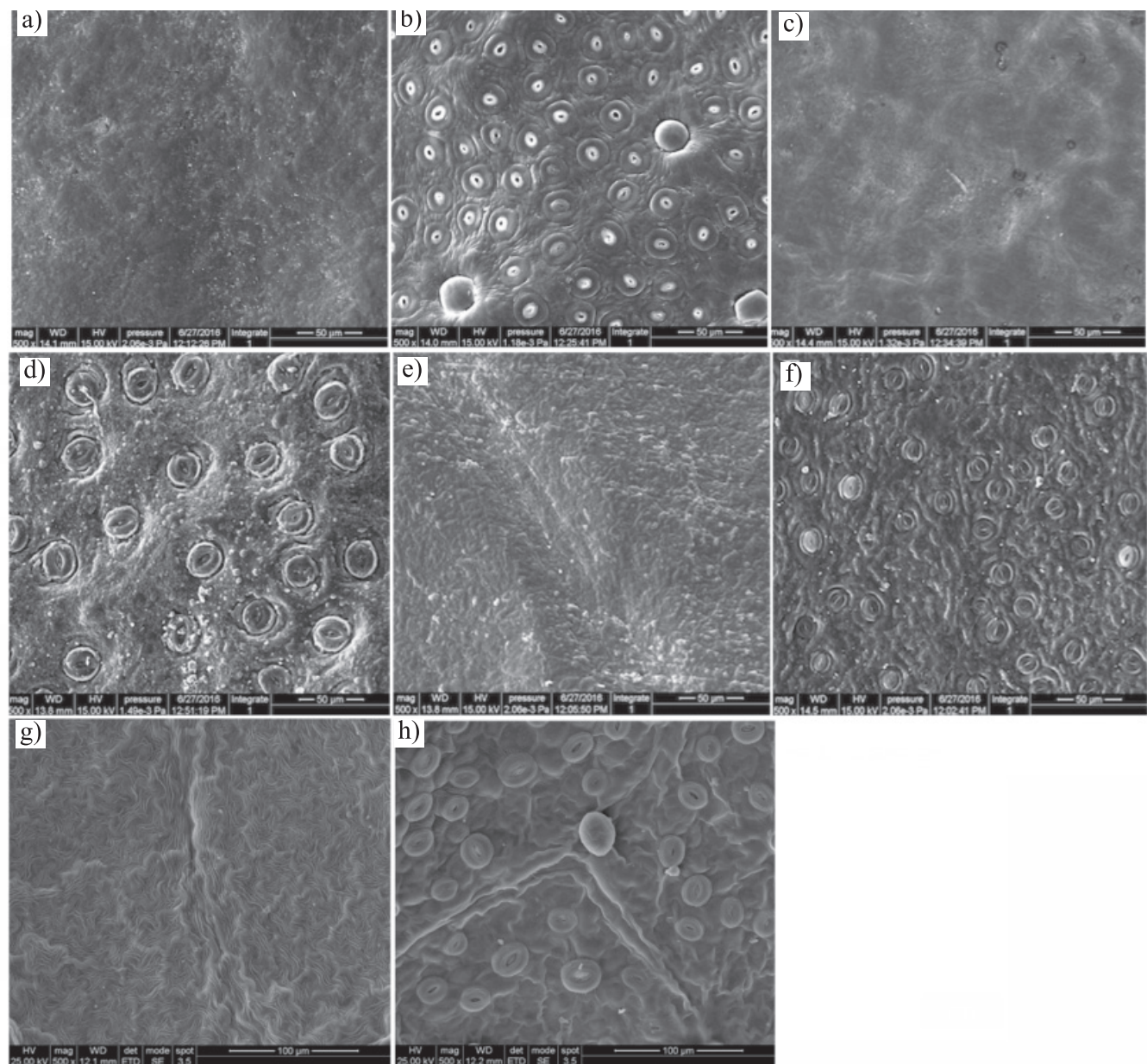

Fig. 6. Scanning electron micrographs of leaves surface: a) O. fragrans, showing a almost closed stomata frequency. b) $O$. fragrans, showing a clear stomata. c) $S$. sumuntia, showing smooth surface. d) S. sumuntia, showing clear stomata along with slight papillose. e) $P$. serrylata, showing irregular convex. f) P. serrylata, showing intensive small stomata. g) F. simplex, showing slight trichome and a deep groove. h) F. simplex, showing glandular and stomata.
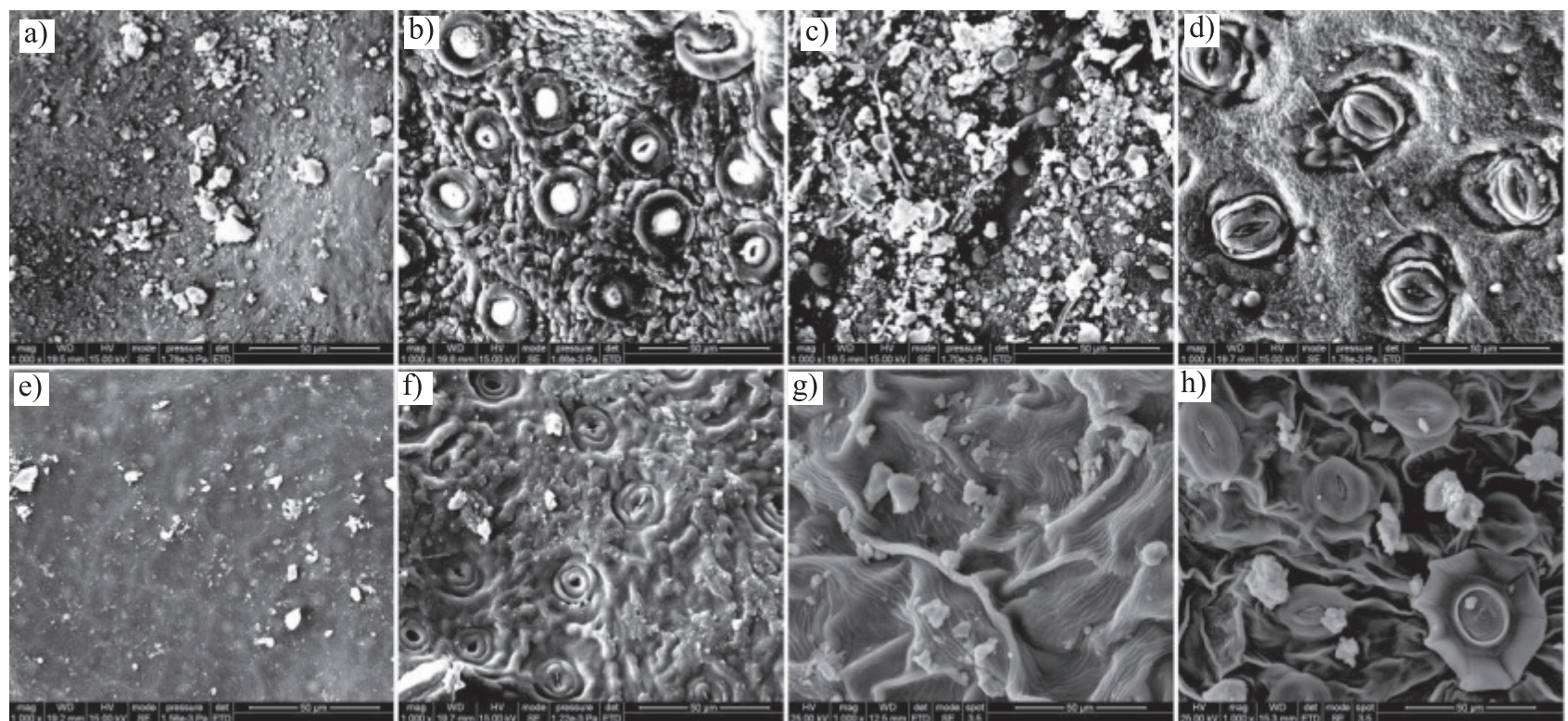

Fig. 7. Scanning electron micrographs of tree species absorbed PM under the 1000 times magnification. a) The adaxial leaf of $O$. fragrans. b) The abaxial leaf of $O$. fragrans. c) The adaxial leaf of $S$. sumuntia. d) The abaxial leaf of $S$. sumuntia. e) The adaxial leaf of $P$. serrylata. f) The abaxial leaf of $P$. serrylata. g) The adaxial leaf of $F$. simplex. h) The abaxial leaf of $F$. simplex. 
of a leaf to accumulate PM and to affect the distribution or particle size of PM is closely related to the leaf surface structure [47-48]. Yang et al. [49] and Räsänen et al. [50] found that $Q$. variabilis accumulated large numbers of fine particles on its adaxial leaf surface.

In our study, concentrations of PAHs in the foliage dust of $F$. simplex was the highest of the four tree species studied, which was associated with particle size of PM in $F$. simplex leaf surface. Grooves are the main parts of the leaf blade, which collect $\mathrm{PM}_{2.5}$ [41], and the deep grooves characteristic of $F$. simplex can intercept more particles. As shown in Figs 5(g-h), few particles were captured near the stomata of $F$. simplex, and the low stomatal density provided the plant with an advantage in the retention of fine particles from a human perspective [49]. Beckett et al. [51] showed that of the broad-leaf species at the most polluted sites at With Dean Park, maple accumulated the most fine particulates. Freer-Smith et al. [52] showed that fly ash particles were more easily captured by those leaves with high surface roughness, such as the presence of leaf hairs, ditch, or raphes, and those with short petioles. It was reported that the particle size of the ultra-fine PM was less than $1 \mu \mathrm{m}$ [53], and thus fine PM is easily intercepted by $F$. simplex. This provided additional reason for the highest accumulation by F. simplex. The results indicated that the micromorphology of $F$. simplex was important for its use as an environmental-quality indicator. On the contrary, $O$. fragrans has been shown to be an inefficient trapper of airborne PM [49]. The size of dust particles trapped on the surface of its leaves was relatively large, and this could explain why we found a lower concentration of PAHs on the surface of these leaves. The capacity of leaves to trap PM was affected by many factors, and leaf structure was the key factor. Another factor to be considered is height of the plant, with the canopy of tall trees being particularly effective at trapping PM that falls from above the tree canopy [54].

\section{Conclusions}

1) We studied the foliar capture of PMs with the concomitant accumulation of PAHs by four tree species. Dust deposited over the leaf surfaces were contaminated with PAHs, which can detrimentally affect human health

2) Leaf surfaces with grooves surrounding the stomata or tomentum played an important role in the capture of air contaminants on leaves. The results showed that there were significant differences among tree species in terms of PAH accumulation capacity.

3) The highest amount of dust accumulation was associated with high concentrations of PAHs. We found that the most efficient species for capturing PM and PAHs was $F$. simplex. Urbanization significantly increased PAH concentrations of foliage dust.

4) An appropriate urban tree is a good accumulator of atmospheric contaminants. The removal of dust by tree species in this study provided further evidence to help environmental planners and researchers select the most suitable tree species for reducing atmospheric dust and PAH contaminants.

\section{Acknowledgements}

This study was financially supported by the Natural Science Major Projects in Jiangsu Province Colleges and Universities (No. 13KJA180002) and the Priority Academic Program Development of Jiangsu Higher Education Institutions (PAPD). The Doctorate Fellowship Foundation of Nanjing Forestry University also is gratefully acknowledged (No. 2149025).

\section{References}

1. IARC. http://monographs.iarc.fr/ENG/Classification/index. php (accessed 19.08. 11). 2011.

2. IARC. Some non-heterocyclic polycyclic aromatic hydrocarbons and some related exposures. Monographs on the Evaluation of Carcinogenic Risks to Humans. 92, 765, 2010.

3. MAHLER B.J., METRE P.C.V., CRANE J.L., WATTS A.W., SCOGGINS M., WILLIAMS E.S. Coal-tarbased pavement sealcoat and PAHs: implications for the environment, human health, and storm water management. Environment Science Technology. 46 (6), 3039, 2012.

4. ALEBIĆC-JURETIĆ A. Airborne polycyclic aromatic hydrocarbons in suspended particulates from the urban atmosphere of rijeka, Croatia. Polycyclic Aromatic Compounds. 35 (1), 91, 2015.

5. TOBISZEWSKI M., NAMIESNIK J. PAH diagnostic ratios for the identification of pollution emission sources. Environmental Pollution. 162, 110, 2012.

6. LI Y., MA J., YANG Z., LOU I. Influence of non-point source pollution on water quality of Wetland Baiyangdian, China. Desalin. Water Treat. 32, 291, 2011.

7. YU B., XIE M., MA L.Q., KAN H., ZHOU Q. Occurrence and possible sources of organochlorine pesticides (OCPs) and polychlorinated biphenyls (PCBs) along the Chao River, China. Chemosphere. 114, 136, 2014.

8. GUNAWARDNA C., GOONETILLEKE A., EGODAWATTA P., DAWES L., KOKOT S. Source characterization of road dust based on chemical and mineralogical composition. Chemosphere. 87, 163, 2012.

9. BELL M.L., MORGENSTERN R.D., HARRINGTON W. Quantifying the human health benefits of air pollution policies: review of recent studies and new directions in accountability research. Environment Science \& Policy. 14, 357, 2011.

10. CALVO A.I., AlVES C., CASTRO A., PONT V., VICENTE A.M., FRAILE R. Research on aerosol sources and chemical composition: Past, current and emerging issues. Atmospheric Research, 120, 1, 2013.

11. MERLO F., ANDREASSEN A., WESTON A., PAN C., HAUGEN A., VALERIO F., REGGIARDO G., FONTANA V., GARTE S., PUNTONI R. Urinary excretion of 1-hydroxypyrene as a marker for exposure to urban air levels of polycyclic aromatic hydrocarbons. Cancer Eqidemiology. Biomarkers \& prevention. 7, 147, 1998.

12. ANDERSON J.O., THUNDIYIL J.G., STOLBACH A. Clearing the air: a review of the effects of particulate 
matter air pollution on human health. Journal of Medical. Toxicology. 8 (2), 166, 2012.

13. ZHANG S.C., ZHANG W., SHEN Y.T., WANG K.Y., HU L.W., WANG X.J. Dry deposition of atmospheric polycyclic aromatic hydrocarbons (PAHs) in the southeast suburb of Beijing. China. Atmospheric Research. 89, 138, 2008.

14. SIMON E., BRAUN M., VIDIC A., BOGYÓ D., FÁ BIÁN I., TÓTHMÉRÉSZ B. Air pollution assessment based on elemental concentration of leaves tissue and foliage dust along an urbanization gradient in Vienna. Environmental Pollution. 159, 1229, 2011.

15. ZHOU Z.X., SHAO T.Y., WANG P.C., GAO C., XU Y.R., GUO E.X., XU L.H., YE Z.Q. PENG X.M., YU C.J. The spatial structures and the dust retention effects of greenland types in the workshop district of Wuhan Iron and Steel Company. Acta Ecologica Sinica. 22, 2036, 2010.

16. OLOWOYO J.O., VAN HEERDEN E., FISCHER J.L., BAKER C. Trace metals in soil and leaves of Jacaranda mimosifolia in Tshwane area, South Africa. Atmospheric Environment. 14, 1826, 2011.

17. NOWAK D.J., DANIEL E.C., STEVENS J.C. Air pollution removal by trees and shrubs in the United States. Urban Forestry \& Urban Greening. 4, 115-123, 2006.

18. RAM S.S., KUMAR R.V., CHAUDHURI P., CHANDA S., SANTRA S.C., SUDARSHAN M., ANINDITA C. Physico-chemical characterization of street dust and resuspended dust on plant canopies: An approach for finger printing the urban environment. Ecological Indicators. 36, 334, 2014.

19. CHAI Y.X., ZHU N., HAN H.J. Dust removal effect of urban tree species in Harbin. China Journal of Applied Ecology. 13 (9), 1121, 2002 [In Chinese].

20. BURKHARDT J. Hygroscopic particles on leaves: nutrients or desiccants? Ecological Monographs. 80, 369, 2010.

21. HWANG H., YOOK S., AHN K., Experimental investigation of submicron and ultrafine soot particle removal by tree leaves. Atmospheric Environment. 45, 6987, 2011.

22. BECKETT K.P., FREE-SMITH P.H., TAYLOR G. Urban woodlands: their role in reducing the effects of particulate pollution. Environment Pollution. 99, 347, 1998.

23. FARMER A. Effects of particulates. Air pollution and plant life. $2^{\text {nd }}$ edition. West Sussex, John Wiley. 187, 2002.

24. LIU L., GUAN D.S., PEART M.R. The morphological structure of leaves and the dust-retaining capability of afforested plants in urban Guangzhou, South China. Environment Science Pollution Research. 19, 3440, 2012.

25. LI Q., CHEN B. Organic pollutant clustered in the plant cuticular membranes: visualizing the distribution of phenanthrene in leaf cuticle using two-photon confocal scanning laser microscopy. Environmental Science \& Technology. 48, 4774, 2014.

26. HOWSAM M., Jones, K.C., Ineson, P. PAHs associated with the leaves of three deciduous tree species. II: uptake during a growing season. Chemosphere. 44, 155, 2001.

27. XU L.Y., SHU Y., HOLLERT H. Aggregate risk assessment of polycyclic aromatic hydrocarbons from dust in an urban human settlement environment. Journal of Cleaner Production. 133, 378, 2016.

28. BARANYAI E., SIMON E., BRAUN M., TÓTHMÉSZ B. , POSTA J., FÁBIÁN I. The effect of a fireworks event on the amount and elemental concentration of deposited dust collected in the city of Debrecen, Hungary. Air Quality Atmospheric Health. 8, 359, 2015.

29. WANG X.T., MIAO Y., ZHANG Y., LI Y.C., WU M.H., $\mathrm{YU}$, G. Polycyclic aromatic hydrocarbons (PAHs) in urban soils of the megacity Shanghai: occurrence, source apportionment and potential human health risk. Science of the total Environment. 447, 80, 2013.

30. OLAJIRE A.A., ALTENBURGER R., KÜSTER E., BRACKW. Chemical and ecotoxicological assessment of polycyclic aromatic hydrocarbon - contaminated sediments of the Niger Delta, Southern Nigeria. Science of the total Environment. 340 (1), 123, 2005.

31. NIELSEN T. Traffic contribution of polycyclic aromatic hydrocarbons in the center of a large city. Atmospheric Environment. 30 (20), 3481, 1996.

32. KHALILI N.R., SCHEFF P.A., HOLSEN T.M. PAH source fingerprints for coke ovens, diesel, and gasoline engines, highway tunnels, and wood combustion emissions. Atmospheric Environment. 29 (4), 533, 1995.

33. WANG D.G., YANG M., JIA H.L., ZHOU L., LI Y.F. Polycyclic aromatic hydrocarbons in urban street dust and surface soil: comparisons of concentration, profile, and source. Archives of Environmental Contamination Toxicology. 56 (2), 173, 2009.

34. SIMCIKI M.F., EISENREICH S.J., LIOYI P.J. Source apportionment and source/sink relationships of PAHs in the coastal atmosphere of Chicago and Lake Michigan. Atmospheric Environment. 33 (30), 5071, 1999.

35. LI Y.X., SONG N.G., YU Y., YANG Z.F., SHEN Z.Y. Characteristics of PAHs in street dust of Beijing and the annual wash-off load using an improved load calculation method. Science of the Total Environment. 581-582, 328, 2017.

36. RAM S.S., MAJUMDAR S., CHAUDHURI, P., CHANDA S., SANTRA S.C., MAITI PK., SUDARSHAN, M., CHAKRABORTY A. Plant canopies:bio-monitor and trap for re-suspended dust particulates contaminated with heavy metals. Mitigation. and Adaptation. Strategies for. Global Change. 19 (5),499, 2014.

37. LEE B.K., DONG T.T.T. Effects of road characteristics on distribution and toxicity of polycyclic aromatic hydrocarbons in urban road dust of Ulsan, Korea. Journal of Hazardous Materials. 175, 540, 2010.

38. WANG W., HUANG M.J., KANG Y., WANG H.S., LEUNG A.O.W. CHEUNG K.C., WONG K.H. Polycyclic aromatic hydrocarbons (PAHs) in urban surface dust of Guangzhou, China: Status, sources and health risk assessment. Science of Total Environment. 409, 4519, 2011.

39. QIAO M., Wang C.X., HUANG S.B., WANG D.H., WANG Z.J. Composition, sources, and potential toxicological significance of PAHs in the surface sediments of the Meiliang Bay, Taihu Lake, China. Environment International. 32, 28, 2006.

40. FREER-SMITH P.H., BECKETT K.P, TAYLOR G. Deposition velocities to Sorbus aria, Acer campestre, Populus deltoides trichocarpa 'Beaupre', Piuns nigra and Cupressocyparis leylandii for coarse, fine and ultra-fine particles in the urban environment. Environment Pollution. 133, 157, 2005.

41. MO L., MA Z.Y., SUN F.B., LUN X.X., LIU X.H., CHEN J.G., YU X.X. Assessing the capacity of plant species to accumulate particulate matter in Beijing China. Plos one.1, 2015.

42. SAEBØ A., POPEK R., NAWROT B., HANSLIN H.M., GAWRONSKA H, GAWRONSKI S.W., Plant species differences in particulate matter accumulation on leaf surfaces. Science of the Total Environment. 427, 347, 2012.

43. WANG J.H., LIU Y.Q., ZOU M. Dust detaining effect of main urban vegetation in Yongchuan, Chongqing. Chinese 
Journal of Environmental Engineering. 7 (3), 1079, $2013 \mathrm{a}$. [In Chinese].

44. XIAO P., JIAO Y.W., PEI T.T., ZHOU Z.X. The effect of adsorbing fine particulate matter (PM2.5) by garden plants: A review. Chinese Journal of Ecology. 33 (9), 2558, 2014.

45. SPEAK A.F., ROTHWELL J.J., LINDLEY S.J. Urban particulate pollution reduction by four species of green roof vegetation in a UK city. Atmospheric Environment. 61, 283, 2012.

46. MURAKAMI M., ABE M., KAKUMOTO Y., KAWANO H., FUKASAWA H., SAHA M., TAKADA H. Evaluation of ginkgo as a biomonitor of airborne polycyclic aromatic Hydrocarbons. Atmospheric Environment. 54, 9, 2012.

47. SHI H., WANG H.X., LI Y., LIU X. leaf surface microstructure of Ligustrum lucidum and Viburmum odoratissimim observed by atomic force microscope (AFM). Acta Ecologica Sinica. 31, 1471, 2013.

48. WANG H., SHI H., LI Y., Seasonal variation in leaf capturing of particulate matter, surface wettability and micromorphology in urban tree species. Frontiers of Environmental Science \& Engineering. 7 (4), 579, 2013b.

49. YANG J., WANG H.X., XIE, B.Z., WANG Y. Accumulation of particulate matter on leaves of nine urban greening plant species with different micromorphological structures in Beijing. Research of Environmental Science. 28 (3), 384, 2015.
50. RÄSÄNEN J.V., HOLOPAINEN T., JOUTSENSAAI J., NDAMC., PASANENP., RINNANA., KIVIMÄÄENPÄÄ, M. Effects of species specific leaf characteristics and reduced water availability on fine particle capture efficiency of trees. Environment Pollution. 183, 64, 2013.

51. BECKETT K.P., FREE-SMITH P.H., TAYLOR G. The capture of particulate pollution by trees at five contrasting UK urban sites. Arboricultural Journal. 24, 1, 2000.

52. FREER-SMITH P.H., HOLLOWAY S., GOODMAN A. The uptake of particulates by an urban woodland: site description and particulate composition. Environment Pollution. 95 (1), 27, 1997.

53. XIE Y.Y., LIANG P., MENG J., HE K., ZANG S.Y. Population sensitive to Material Sources Area of StandDust Fallouts in Harbin City and Their Source Analysis. Geography and Geo-Information Science. 06, 51, 2009. [In Chinese].

54. JAMIL S. ABILASH P.C., SINGHI A., BEHI H.M. Fly ash trapping and metal accumulating capacity of plants: Implication for green belt around thermal power plants. Landscape and Urban Planning. 92 (2), 136, 2009. 